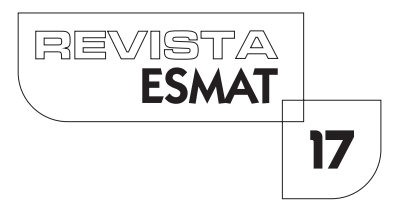

\title{
O JUDICIÁRIO BRASILEIRO E SUAS ANOMALIAS: QUANTIDADE DE PROCESSOS E QUALIDADE DAS DECISÕES
}

\author{
THE BRAZILIAN JUDICIARY AND ITS ANOMALIES: \\ NUMBER OF PROCESSES AND QUALITY OF DECISIONS
}

João Carneiro Duarte Neto

Mestrando em Direito, pela Faculdade Guanambi/BA. Juiz de Direito Titular da $2^{a}$ Vara Cível, Criminal e de Execução Penal da Comarca de Manga do Tribunal de Justiça de Minas Gerais (TJMG). Juiz Eleitoral da $166^{\text {a }}$ Zona Eleitoral - TRE/MG. Pós-Graduações em Direito Administrativo, Direito Constitucional, Direito Eleitoral e Direito Processual Civil. Pesquisador Capes da linha de pesquisa Ética, Autonomia e Fundamentos do Direito, vinculada ao PPGD da Faculdade Guanambi/BA. Palestrante. joaocduarten@hotmail.com.

\section{RESUMO}

A presente pesquisa coloca em destaque duas grandes anomalias do Judiciário brasileiro, quais sejam, a enorme quantidade de processos para cada magistrado e a duvidosa qualidade das decisões judiciais. Como forma de enfrentamento do primeiro problema, desenvolveu-se a temática da figura do juiz-gestor. Mostraram-se as inúmeras atividades atípicas de cunho administrativo e de gestão a que o magistrado termina por se ver envolvido do dia a dia forense, bem como sua falta de preparação específica para tal. Ressaltou-se a necessidade de que os magistrados tenham conhecimentos de gestão pública aplicada à gestão judiciária como fator otimizador da eficiência da prestação jurisdicional. Já para o enfrentamento da situação crítica do Judiciário no que tange à qualidade das decisões judiciais, exortou-se a necessidade de se desenvolver uma teoria da decisão que prestigie teoria e prática. Ressaltou-se que o princípio do livre convencimento motivado do julgador foi atualizado pelo Código de Processo Civil, de 2015, e criticado como sendo fator obstaculizador ao enfrentamento do conteúdo das decisões judiciais. Realizou-se estudo dos contributos da filosofia do direito e da hermenêutica filosófica, conciliando-os com a tradição fática experimentada dos juízes. Por fim, exorta-se a necessidade de união entre as Escolas da Magistratura e as Faculdades de Direito como forma de combate aos dois grandes problemas do Judiciário nacional. Utilizou-se essencialmente da metodologia de pesquisa bibliográfica no desenvolvimento deste artigo.

PALAVRAS-CHAVE: Judiciário. Gestão Judiciária. Teoria da Decisão. Escolas da Magistratura. Faculdades de Direito.

\section{ABSTRACT}

The present research highlights two major anomalies of the Brazilian Judiciary, namely, the enormous number of cases for each magistrate and the dubious quality 
of judicial decisions. As a way of coping with the first problem, the theme of the Judge-Manager was developed. There have been a number of atypical administrative and management activities to which the magistrate ends up being involved in the dayto-day forensics, as well as his lack of specific preparation for it. It was emphasized the need for magistrates to have knowledge of public management applied to judicial management as an optimizing factor of the efficiency of the jurisdictional provision. In order to deal with the critical situation of the Judiciary regarding the quality of judicial decisions, the need to develop a theory of decision that emphasized theory and practice was exhorted. It was emphasized that the principle of free convincing of the judge was updated by CPC/20I 5 and criticized as being an obstacle to the content of judicial decisions. The contributions of philosophy of law and philosophical hermeneutics have been studied, reconciling them with the experienced factual tradition of the Judges. Finally, there is a need for a union between the Schools of the Judiciary and the Faculties of Law as a way of combating the two great problems of the national judiciary. We used essentially the methodology of bibliographic research in the development of this article.

KEYWORDS: Judiciary. Judicial Management. Decision Theory. Schools of the Judiciary. Law Schools.

\section{INTRODUÇÃO}

Dentre as formas de solução de conflitos, existentes em toda sociedade, destaca-se a jurisdição. Essa atividade de responder à sociedade sobre os problemas apresentados ao Judiciário, por meio de um processo, tem como protagonista o juiz.

$\bigcirc$ juiz moderno tornou-se polivalente na prática, gerando potenciais distorções de sua atividade, tendo em vista estar apenas parcialmente preparado para as atividades que lhe são exigidas. Isso frustra o papel que tem de garantidor dos direitos fundamentais ao prolatar suas decisões.

Questiona-se se o fortalecimento da legitimidade do judiciário, e a efetividade do direito passaria pela formação do juiz em matérias típicas de administração pública, posto funcionar como gestor do Poder constitucionalmente encarregado de prestar o serviço de jurisdição à população. Seria então uma questão de gestão, em outras palavras, de administração judiciária?

Lenio Luiz Streck, Rafael Tomaz de Oliveira e André Karam Trindade (2013) observam que as propostas de gestão têm se mostrado como tendência para a solução da efetividade processual no Brasil. Denominaram o fenômeno como "ideologia da gestão". E, adiante, esclarecem: "Esta administração empresarial da justiça apresenta três consequências: (a) a primazia do mercado como fator de decisão; (b) a redefinição das estruturas organizativas; e (c) a existência de indicadores de performance". $(20 \mid 3$, p. | 8$)$ 
A hipótese vislumbrada perpassa pela necessidade de que o juiz deva ter conhecimento teórico para uma gestão correta do serviço de prestação jurisdicional, que permita uma atuação duplamente técnica, matéria jurídica e de administração pública, resultando numa maior efetividade do direito.

Seguindo no mesmo caminho e tornando clara e urgente a necessidade de os juízes passarem a ter conhecimento de administração da justiça, cita-se também trecho da obra de Carlos H. B. Haddad e Luís A. Capanema Pedrosa, Administração Judicial Aplicada:

Os tribunais são apontados como uma das organizações mais burocráticas do Estado e, por força de sua estrutura, sua organização e funcionamento representam forte fator de bloqueio ao aumento da eficácia, eficiência e qualidade da justiça. $\bigcirc$ incremento das reformas da gestão da justiça está em consonância com a adoção de nova concepção da administração pública, repousada no abandono do modelo burocrático e na adoção dos modelos gestionário e da qualidade total. (HADDAD e PEDROSA, 20।4, p. 79)

Assim, acredita-se que a aproximação de conhecimentos técnicos de gestão com a atividade judicante acarretará um incremento na efetividade do Direito, maior segurança jurídica na obediência dos procedimentos e, por conseguinte, fortalecimento da democracia, pautando o juiz-gestor de forma mais cartesiana e menos subjetiva.

Ingressando no contexto da qualidade das decisões judiciais, demonstra-se a inviabilidade de importações prontas de teorias da decisão de outros países, exigindo-se estudo, enfrentamento e construção de uma teoria pátria, adequada aos nossos problemas e aos nossos operadores do fenômeno jurídico.

Destaca-se que o princípio do livre convencimento motivado está ultrapassado e não há mais que se falar em liberdade na apreciação das provas, o que exige do julgador mais responsabilidade institucional no ato da prolação de uma decisão judicial.

Foram aproveitadas as contribuições da filosofia do direito de Robert Alexy, sem deixar de denunciar a recepção equivocada pelos juristas brasileiros, bem como a de Ronald Dworkin, com a obrigação institucional de revolver as entranhas do direito em busca de uma resposta correta.

A necessidade de melhora da qualidade das decisões judiciais será tratada sob o viés da hermenêutica filosófica de Gadamer, partindo-se do pressuposto de que o tratamento jurídico dos fenômenos é reflexo do paradigma filosófico em que está situado. Ressaltou-se a alteração paradigmática do conhecimento, saindo do foco antigo da essência das coisas (mito do dado) para o sujeito assujeitador da modernidade (filosofia da consciência), até se chegar à discursividade via linguagem na relação equivalente intersubjetiva (relação sujeito/linguagem - sujeito/linguagem).

Por fim, traçou-se paralelo entre o desenvolvimento da hermenêutica como um esforço teórico e prático com a necessidade de que a construção de técnicas para 
enfrentamento das anomalias destacadas deverão ser via somatório de esforços do estado da arte teórica em que se encontram tais estudos - Faculdades de Direito com a tradição fática experimentada dos juízes, via participação das Escolas da Magistratura dos Tribunais brasileiros.

\section{ANOMALIAS DO JUDICIÁRIO BRASILEIRO}

A existência de conflito social é fenômeno inerente à convivência humana, é previsível e, em níveis equilibrados, gerador de desenvolvimento social, pois tem forte apelo impulsionador de novos comportamentos que terminam criando organizações inovadoras.

De outra forma, níveis exagerados de conflitos sociais são nocivos à manutenção e evolução da sociedade, o que deve ser combatido e controlado.

Há várias formas de resolução de conflitos sociais, sendo métodos autocompositivos (mediação, conciliação, negociação e autotutela) e heterocompositivos particular (arbitragem) e estatal (Judiciário). É sobre este último que a pesquisa se debruçará.

Espera-se de um órgão estatal com a incumbência de resolução de conflitos sociais um aparato estrutural e humano capaz de fornecer um serviço de prestação jurisdicional de maneira estável, seguro, firme, justo, célere, efetivo, equilibrado, previsível, de fácil e barato acesso. Características quantitativas e qualitativas exigidas da atividade típica do Poder Judiciário.

Ocorre que é facilmente perceptível a constatação de problemas na prestação do serviço de justiça brasileiro, como a dificuldade de acesso ao Judiciário, que ainda teima em ficar distante da sociedade carente e semianalfabeta; a demora excessiva para se chegar ao fim das demandas judiciais, processos que se arrastam por longos anos até o trânsito em julgado; sociedade extremamente demandante e dependente do Judiciário para solução de questões simples do dia a dia; seletividade da justiça criminal e, por conseguinte, da execução penal, devido leis penais direcionadas às classes menos favorecidas e órgãos de persecução penal tendenciosos ou com dificuldades de apuração dos ilícitos de "colarinho branco"; influências políticas nos Tribunais brasileiros, potencializadas pela previsão do quinto constitucional e nomeações por chefes do Poder Executivo; dentre outras tantas dificuldades e equívocos da estrutura e funcionamento do Poder Judiciário.

Ademais, há enorme quantidade de processos tramitando em relação à pequena quantidade de juízes, o que torna o trabalho do juiz humanamente impossível. A pessoa do magistrado termina por carregar toda essa responsabilidade. Nesse sentido, inevitável se lembrar da figura metafórica do juiz Hércules, aquele de capacidade, sabedoria, paciência e sagacidade sobre-humana (DWORKIN, 20 I0, p. 165).

Nessa conjuntura, surgem juízes com posturas ativistas, trazendo desequilíbrio entre os Poderes e insegurança jurídica, o que, em última análise, também viola a democracia.

Esse problema já foi identificado por Lenio Luiz Streck, Rafael Tomaz de Oliveira e André Karam Trindade, no artigo $\bigcirc$ "cartesianismo processual" em terrae brasilis: 
a filosofia e o processo em tempos de protagonismo judicial. Vale a transcrição de trecho do texto:

Ocorre que, por detrás do protagonismo judicial, escondese uma tendência que, de uma forma bem específica, Ihe impulsiona, oferecendo uma espécie de "legitimidade" (evidentemente uma legitimidade econômico-formal, e não democrático-material). Segundo asseveram os partidários dessa tendência, o problema do sistema de justiça e do nosso modelo processual pode ser resumido e bem compreendido como um problema de gestão. Esse problema divide-se em gestão no nível macro e gestão no nível micro. No nível macro, coloca-se o problema do funcionamento do próprio sistema de justiça, com destaque para o gerenciamento funcional dos serventuários; já no nível micro, tem-se problemas de ordem burocráticoprocessual e de gerenciamento de questões internas ligadas ao andamento do processo, especificamente considerado. As propostas de solução desse problema de "gestão" que acomete o Poder Judiciário chegam, no limite, a indicar um modelo empresarial privado para a gestão e a organização do sistema de justiça. (STRECK, OLIVEIRA e TRINDADE, 2013, p. 17).

Como resposta ao problema da quantidade sufocante de processos, o Conselho Nacional de Justiça e os Tribunais brasileiros têm reagido com várias inovações no sentido de melhorar a prestação jurisdicional. Uma das grandes vertentes de atuação é a exigência de mudança na postura dos magistrados, os quais devem se portar como juízes-gestores.

Ademais, somando-se ao problema da quantidade exagerada de processos, também salta aos olhos a ausência de previsibilidade mínima das decisões judiciais. Há forte conteúdo discricionário nas decisões judiciais. Existem as mais variadas e conflitantes jurisprudências nos Tribunais brasileiros sobre qualquer matéria. Não se conseguem mecanismos de uniformização eficientes. Esse é o ponto de maior interesse da busca por uma teoria da decisão que consiga aplacar tal distorção na prestação jurisdicional. Nesse sentido:

Desse modo, considerando que no interior da dogmática jurídica a interpretação continua a ser entendida como a escolha de um sentido que advém da consciência do julgador, o que se verifica é que, no Brasil, a vulgata da ponderação não está aumentando o grau de racionalidade das decisões judicias, mas potencializando o subjetivismo e, sob o álibi teórico da proporcionalidade, instituindo uma justiça cada vez mais lotérica. (TRINDADE, 2013, p. 4). 
A história brasileira de formação cultural jurídica de origem civil law, em que se tem um caso concreto e todo o ordenamento jurídico para encontrar a resposta, somado à inexistência de uma técnica segura e objetiva para tal desiderato, talvez ajude a explicar o estágio atual de insegurança jurídica a que a população brasileira é submetida.

Sistemas judiciários de origem common law possuem uma tendência de irem se purificando e afunilando o conteúdo das decisões judiciais. Vejamos: o hábito de se partir de um caso concreto julgado anteriormente, diferentemente de se partir do ordenamento jurídico como no civil law, provoca um entrechoque entre os próprios casos concretos e entre os julgadores, ocasionando, ao longo dos anos, fenômeno de lapidação das decisões judiciais, de coerência das respostas judiciais aos casos assemelhados, terminando por gerar certa estabilidade e segurança jurídica na prestação jurisdicional.

No sistema civil law não há a preocupação de melhorar a reposta estatal do Poder Judiciário mediante os casos concretos atuais em relação àqueles já submetidos a julgamento, pois os julgadores não se sentem vinculados ao que seus pares já decidiram no passado, mesmo que em casos semelhantes. Paira no ar certa liberdade de se buscar no ordenamento jurídico, como um todo, a melhor resposta, o que provoca uma abertura de decisões possíveis incontáveis. Assim, com base em alegado livre convencimento, os julgadores permanecem num limbo de liberdade com moldura limitadora por demais elástica.

\section{ENFRENTANDO A QUANTIDADE EXCESSIVA DE PROCESSOS}

Naturalmente, o contexto forense em que o juiz de direito é inserido, logo após sua aprovação num dos concursos públicos mais difíceis do Brasil, exigirá dele habilidades até então alheias à sua preparação profissional para a carreira e, de certa forma, inesperadas.

Pode-se dizer que os recém-chegados julgadores são literalmente pegos de surpresa quanto às inúmeras exigências administrativas relevantes para a prestação jurisdicional. Imaginava-se que juiz de direito apenas julgava, porém se constata que ele julga e administra o complexo serviço público de prestação jurisdicional.

A surpresa é comprovada tendo em vista que as normativas que tratam da carreira e do ingresso no cargo de juiz de direito nada mencionam acerca das exigências de conhecimento de gestão inerentes ao cargo.

A Constituição Federal, de 1988, em especial nos artigos 96 e 99, descreve atribuições de gestão direta e reconhece a autonomia administrativa e financeira dos tribunais, porém sem potencial indicativo da capilaridade de tais atribuições para todas as unidades judiciárias lideradas por magistrados.

As principais normativas infraconstitucionais que tratam da carreira do magistrado concentram-se no regramento da atividade jurisdicional, ato de julgar, silenciando acerca dos atos de gestão. Cita-se a Lei Orgânica da Magistratura (LOMAN), Lei 
Complementar n 35, de 1979; Código de Ética da Magistratura, aprovado na 68 ${ }^{\mathrm{a}}$ Sessão Ordinária do Conselho Nacional de Justiça, em 6 de agosto de 2008; e Resolução n 75, de 2009, do Conselho Nacional de Justiça, que trata do concurso público de ingresso na magistratura.

O doutrinador e magistrado Nagib Slaibi Filho alerta:

Ressalte-se que as funções administrativas do Poder Judiciário não constituem o seu objeto de atuação ou atividade-fim - que é a prestação jurisdicional -, mas mero instrumento de realização dessa atividade, de nítido conteúdo político, exercido por membros do Poder e que não se pode limitar pela função secundária. (SLAIBI FILHO, 2016, f. 137).

Nesta pesquisa, não se quer ressaltar as atividades administrativas dos tribunais, como realização de concurso público para servidores e membros, organização interna e concessões de direitos funcionais dos integrantes, dentre várias outras, pois já esperadas e conhecidas do grande público e, normalmente, concentradas na sede do tribunal, possuindo estrutura administrativa especializada responsável para tal.

○ enfoque da presente pesquisa são as atividades de gestão desenvolvidas diretamente pelos juízes nas unidades judiciárias (Varas ou Seções) conjuntamente com a atividade-fim de julgadores.

magistrado de postura ensimesmada, mantendo seu universo de atuação limitado entre gabinete e sala de audiência, certamente terá sérias dificuldades para que sua unidade judiciária preste um bom serviço de entrega de justiça. Pois o acesso à justiça não pode ser apenas uma porta de entrada, mas sim uma "máquina" organizada, acolhedora e eficiente para resolução de conflitos, sendo a decisão judicial apenas um item dessa grande e complexa "engrenagem".

Uma das atividades afetas ao julgador é o relacionamento com as instituições dos outros poderes.

Com o Poder Executivo, num plano local e regional, destacam-se os municípios, os quais, por vezes, firmam convênios com os tribunais para cessão de servidores para exercerem suas atividades no ambiente forense. Ainda, vários casos de empréstimos de imóveis para funcionamento da estrutura do Judiciário. Tudo isso ao mesmo tempo em que são grandes demandantes da comarca, sejam como autores (execução fiscal, por exemplo) ou como requeridos (cobrança de verbas trabalhistas). Tais interesses não podem ser confundidos, cabendo ao juiz deixar tudo muito claro e transparente a cada contato com os prefeitos e/ou secretários de Governo. O mesmo raciocínio no caso de contato com os gestores nos planos estadual e federal.

Os estudos de segurança pública apontam amplamente no sentido de que não podem ser vistos apenas como caso de polícia. Costumeiramente, a Polícia Civil e 
a Militar estão sucateadas e somente conseguem funcionar com ajuda de convênios com municípios e da população diretamente interessada e vítima da criminalidade. Nesse cenário, os juízes são frequentemente procurados para auxiliar em tais dificuldades, seja para provocar as instâncias superiores, seja para destinar verbas de prestação pecuniária ou bens apreendidos.

Somando-se a isso, o fenômeno da criminalidade certamente deságua nos escaninhos forenses, pois o juiz de direito de qualquer comarca que não se preocupa com os índices de criminalidade local passa a ser vítima de uma equação matemática forense asfixiante. Explica-se: mais crimes numa comarca geram mais Boletins de Ocorrência e Inquéritos Policiais, o que gera mais denúncias pelo Ministério Público, acarretando mais distribuição de processos, logo mais audiências de instrução e mais sentenças. Tal equação dificulta que a Meta 0 I do Conselho Nacional de Justiça seja atingida, pois esta prevê que a Unidade Judiciária deve julgar mais processos do que são distribuídos.

Portanto, o trabalho deficiente das polícias e de todos os envolvidos na segurança pública repercute em inevitável congestionamento da máquina de prestação de justiça. Assim, um bom juiz-gestor procura provocar melhora na eficiência do trabalho de todos os atores com potencial de reduzir a criminalidade, quais sejam, as polícias, guardas municipais, escolas, a rede de atendimento às pessoas carentes, a rede de atendimento da infância e juventude, o sistema penitenciário e vários outros.

Todos esses contatos, cobranças e provocações são de cunho eminentemente administrativo e político, pois paralelos aos processos judiciais e às atividades judicantes. Exigem-se do juiz conhecimento e habilidade quanto ao funcionamento da lógica de um sistema diferente do Judiciário, pois o sistema político do executivo e legislativo envolve atores diversos e com interesses mais diversos ainda. Todas essas atividades o julgador deve fazer sem deixar que sua imparcialidade jurisdicional seja afetada.

A execução penal é híbrida por natureza, pois a Lei n 7.210, de 1984, prevê um entrelaçamento entre órgãos do Poder Executivo e do Poder Judiciário, além da sociedade. $\bigcirc$ juiz da execução penal literalmente não consegue aplicar a lei devido a uma sabida, ilegal e abjeta ineficiência do Estado. O sistema penitenciário brasileiro é injusto, seletivo, deficitário e contrário aos direitos humanos.

Ocorre que os juízes corregedores dos presídios terminam ficando numa situação sem saída prática viável, em verdadeiras escolhas trágicas. Ou interditam a unidade prisional - o que terminará prejudicando ainda mais o sistema penitenciário e a segurança pública, pois os efeitos repercutirão nas outras unidades e na criminalidade - ou adotam posturas radicais, seja deixando todos no regime fechado, postura abusiva, seja autorizando todos a cumprirem no regime domiciliar, o que é uma falácia deliberada, impunidade total, pois não há fiscalização. $\bigcirc$ que fazer?!

Na prática, o que muito se vê são juízes vocacionados, preocupados com o sistema penitenciário, que conseguem ir driblando as deficiências do Estado em prol 
de uma execução penal minimamente aceitável. De outra banda, inevitavelmente terminam por se distanciarem da legalidade estrita em busca de adaptações à Lei de Execução Penal. Grave drama social, político e jurídico vivenciado pelos juízes de Execução Penal brasileiros diariamente.

É atribuição dos juízes de direito a correição extrajudicial, ou seja, eles são os corregedores dos delegatários das serventias extrajudicias. Os Tribunais de Justiça são os responsáveis pela realização dos concursos públicos para os titulares dos cartórios do Estado, fiscalização da prestação dos serviços, adequada cobrança dos emolumentos e recolhimento das taxas judiciárias de fiscalização. Assim, juízes de direito realizam correições ordinárias e extraordinárias em todos os cartórios de cada Estado.

Ainda, há inúmeras atividades administrativas dos juízes da Infância e Juventude relacionadas à fiscalização para o bom funcionamento de casas de abrigo, acolhimento, creches públicas e assemelhados. Tais visitas e fiscalizações forçam contatos diretos com administradores do Poder Executivo, geralmente esbarrando na limitação orçamentária e na realidade fiscal de cada município.

Quanto ao relacionamento com os membros do Ministério Público e com os advogados, na atividade tipicamente jurisdicional, esta é resolvida via recurso próprio, evoluindo o caso para as instâncias superiores, sem maiores complicadores. Entretanto, os grandes questionamentos circundam as decisões da rotina forense e questões de relacionamento pessoal, quais sejam, atendimentos pela Secretaria e pelo juiz; cargas de processo; celeridade na tramitação; horários e frequências das audiências; descortesias no tratamento; comportamentos contrários à ética; crimes contra a administração da justiça e outros. Situações as mais diversas possíveis que demandam habilidades dos magistrados que estão afetas a outras ciências que não a jurídica.

Outro drama dá conta de ocorrências de invasões de Fóruns pelo Brasil, donde são subtraídas armas de fogo apreendidas, com prejuízo imensurável aos processos e à segurança pública. $\bigcirc$ contato com o Exército Brasileiro deve ser direto, regular e constante para a devida, legal e segura destinação das armas de fogo apreendidas em processos.

Quanto aos colaboradores da unidade judiciária, servidores, contratados por empresas terceirizadas, servidores cedidos por entes públicos, nomeados em cargos em comissão, todos os recursos humanos do Fórum também merecem a atenção individualizada por juízes de direito diretores do Foro, no que tange às questões de direitos trabalhistas e funcionais, como férias, licenças, folgas, horas-extras e compensações. E mais, todas as questões correcionais envolvendo desvios de conduta pelos servidores.

Outro autor que já identificou o problema e a necessidade de novas posturas foi Antônio Ernani Pedroso Calhao, em Princípio da Eficiência na Administração da Justiça:

A estrutura organizacional do Poder Judiciário foi moldada para lidar com sua atividade finalística que é essencialmente jurídica. (...) A função administrativa, como já dito, é 
exercida como atividade atípica modelada, como em toda Administração Pública, pela burocracia weberiana.

Se de um lado, no antigo cenário, dúvidas pairavam acerca da eficiência e sua congruência com o modelo administrativo da Justiça, hoje, após a vigência das medidas apontadas, uma nova perspectiva se abre para a otimização e modernização da justiça. (CALHAO, 2007, p. I56)

As atividades administrativas e de gestão pelos juízes ficam muito claras quando do exercício da Direção do Foro, ocasião em que há a concentração das várias incumbências de gestão do prédio do Fórum, de arquivos, de logística, estratégicas, de projetos, de tecnologia da informação, cartorário, de recursos humanos, financeiro e outras na pessoa do juiz diretor do Foro. Este, normalmente, continua exercendo suas atividades jurisdicionais cumulativamente.

Observa-se, portanto, que as inúmeras atividades não podem mais ser executadas sem profissionalização, sem conhecimento técnico da ciência da administração pública voltada ao Judiciário.

A gestão judiciária deve ser voltada para a qualidade total e, nesse contexto, com o objetivo de gerar eficiência em todo o Judiciário nacional tem-se empregado, embrionariamente ainda, o planejamento estratégico no Judiciário, o qual concebemos como uma ferramenta importantíssima da administração, capaz de prescrever políticas judiciárias que reflitam soluções para os problemas do sistema judiciário brasileiro, apresentando métodos de realização de diagnósticos e de estratégias aptas a orientar as ações dos gestores judiciários, trazendo, a reboque, a salutar impessoalidade às gestões dos Tribunais, a continuidade administrativa (independentemente da alternância dos gestores) e a almejada eficiência da Administração Pública, constitucionalmente prevista no art. 37, caput, CR. (REIS, 2010, f. 57).

$\mathrm{Na}$ atividade tipicamente jurisdicional em si, também se faz necessário planejamento estratégico e gestão processual, sob pena de o Juiz não conseguir vencer satisfatoriamente tamanha demanda.

A resposta jurisdicional constitucionalmente adequada é o resultado da atuação concatenada de um serviço público judiciário em que vários atores participam. Cabe ao juiz de direito reger tal organização, de forma a conseguir que todas as engrenagens funcionem da melhor maneira possível.

setor de Distribuição, Contadoria, Conciliação, Assistência Social, Mandados, Secretaria, Gabinete, Direção do Foro, todos os partícipes dessa prestação jurisdicional devem funcionar de forma perfeitamente concatenada e eficiente. Espera-se assim que o juiz de direito seja o grande líder dessa máquina estatal de entrega de Justiça. 
Para tal função, não basta boa vontade, faz-se necessário conhecimento acerca de gestão pública aplicada ao Judiciário e gestão processual.

No plano endoprocessual, as iniciativas dos juízes são variadas, isoladas e de inspiração própria. $\bigcirc$ juiz deve zelar pelo devido processo legal, de forma justa e célere para as partes. Boas técnicas de gestão processual podem ajudá-lo nessa importante tarefa.

"gerenciamento de processos" pode ser compreendido como o planejamento da condução de demandas judiciais em direção à resolução mais adequada do conflito, com o menor dispêndio de tempo e custos. Depende de uma postura ativa do juiz no controle do andamento dos feitos e organização da unidade judiciária. Seus mecanismos básicos são o envolvimento imediato do juízo com as questões da lide, a abertura para a resolução alternativa do conflito e o planejamento do andamento e dos custos do processo. (ALVES DA SILVA, 20 I0, f. 35)

A observação consciente e atenta do julgador para o todo da atividade de prestação jurisdicional de cada unidade judiciária, analisando as rotinas, os pontos de contato entre Gabinete e Secretaria, utilizando-se de relatórios/mapas gerenciais fornecidos pelos sistemas de consulta de cada Tribunal, identificação de "gargalos" no fluxograma de tramitação dos processos, os fluxos de trabalho de cada setor, certamente farão brotar ideias de gerenciamento com potencial de otimizar o serviço de justiça.

Quando se consegue aliar essa atenção dada pelo juiz na busca de melhoras à prestação jurisdicional com conhecimento técnico de elementos de gestão pública e até de administração privada, passado tudo pelo crivo do devido processo legal, certamente obtém-se uma prestação jurisdicional mais eficiente.

A figura do juiz-gestor tem ganhado força e é grande aposta de tribunais brasileiros numa estratégia para enfrentar os asfixiantes números crescentes de demandas judiciais. Chegou-se à conclusão de que não adianta mais a velha e repetida solução de aumentar a estrutura física e humana como resposta à crescente litigiosidade. Assim,

Nesse passo, a adoção de um modelo de gestão judiciária estruturado por meio do desdobramento do Planejamento Estratégico no âmbito das Unidades Judiciárias de Primeiro Grau, pode consubstanciar importante política pública complementar e integradora sensível para: redução dos déficits de produtividade; ressignificação da autoimagem funcional de magistrados e servidores; interligação e utilização de técnicas de Administração Judiciária e de Gestão por Competências e desenvolvimento de habilidades e atitudes gerenciais que permitam a tradução dos conhecimentos adquiridos em melhoria efetiva dos serviços judiciários. (VALLE, 2017, f. 16) 
Do exposto, conclui-se que atividades administrativas realizadas pelo magistrado definitivamente também fazem parte do seu cotidiano, restando agora ao Conselho Nacional de Justiça e aos Tribunais, por meio das Escolas da Magistratura, promoverem conhecimento técnico de gestão pública aplicada à gestão judiciária aos responsáveis em cada Unidade Judiciária, em especial aos juízes. Para tal, certamente necessitarão de parcerias acadêmicas, locus natural de fonte do conhecimento teórico. $\bigcirc$ exercício de tais atividades de forma atécnica, intuitiva ou equivocada tende a gerar posturas abusivas, inadequadas e, por vezes, ativistas, invasoras de outras searas, o que deve ser evitado e combatido.

\section{ENFRENTANDO A QUALIDADE DAS DECISÕES JUDICIAIS}

Partindo-se do reconhecimento de que o texto normativo não seria suficiente para garantir a correção do direito, somado com a preocupação do conteúdo do direito, tem-se o desenvolvimento de teorias que visam à superação do positivismo jurídico, ou seja, superação do método meramente silogístico de adequação direta do fato à norma.

[...] a incorporação dos conteúdos do direito racional moderno (direitos fundamentais, princípio da democracia, Estado de direito e social) às suas constituições ocidentais provocará uma abertura da discussão jurídica no âmbito dos postulados da correção moral, exigir-se-á, desde aí, uma atitude de redefinição da tarefa metodológico-jurídica, que, agora, precisará desenvolver um procedimento embasado na efetivação daqueles conteúdos. Esta tarefa encontrará na Teoria do Discurso seu substrato teórico, haja vista que esta incorpora junto à sua formação os postulados regulativos da autonomia e universalidade, tão próximos senão identificados com a realização do próprio princípio da democracia. (DUARTE, 2004, ff. 5 I e 52)

As novas teorias foram alvo de diversas críticas no sentido de prejuízos à segurança jurídica, de subjetivismos, de arbitrariedades e impossibilidade de controle racional das decisões. Em sentido contrário, diversas teorias defendem a possibilidade de construir uma teoria racional que consiga conciliar todos esses elementos, dentre eles às do alemão Robert Alexy.

Sob o argumento da correção, no contexto da jurisprudência dos valores, Alexy divide norma em regras e princípios, estes carregam carga valorativa e moral para dentro do direito formal. Assim, tenta-se tornar jurídico o conceito de validade e de invalidade, argumentos até então externos ao direito. E a atitude de considerar inválidas normas absolutamente injustas é feita dentro de uma teoria discursiva impregnada de racionalidade argumentativa comunicacional de origem Habermasiana. Assim: 
A distinção entre regras e princípios constitui, além disso, a estrutura de uma teoria normativo-material dos direitos fundamentais e, com isso, um ponto de partida para a resposta à pergunta acerca da possibilidade e dos limites da racionalidade no âmbito dos direitos fundamentais. (ALEXY, 2017, f. 85)

No contexto pós 2a Guerra Mundial, Robert Alexy encontra farto material de pesquisa na produção jurisprudencial da Corte Constitucional Federal Alemã, para desenvolver uma teoria discursiva racional voltada ao universo de uma necessidade da argumentação jurídica em busca de correção do direito, bem como cria técnicas de ponderação envolvendo os conflitos fáticos de direitos fundamentais.

Essa pretensão de correção, que ocupa papel crucial no pensamento do autor, deve ser explicada a partir da teoria do discurso de Jünger Habermas, que dá fundamentação à teoria da argumentação elaborada por Alexy. Por isso não há exagero na afirmação de Manuel Atienza de que "a teoria de Alexy significa, por um lado, sistematização e reinterpretação da teoria do discurso prático habermasiana; por outro, extensão dessa tese para o campo específico do Direito". (apud BUSTAMANTE, 2008, f. I53)

Alexy não promete em sua teoria um único resultado certo e exato, mas sim um resultado discursivamente aceitável, o qual possui correção. E tal resultado - discursivamente aceitável - é obtido com a aplicação e respeito às regras de um debate dialógico por meio de argumentos práticos gerais e jurídicos.

As regras do discurso passam por fundamentações de ordem técnica (regras de meios para atingir fins); empírica (regras que regem de fato); definitória (jogo de linguagem de fato ou hipotético); e pragmático-universal ou transcendental (a validade de algumas regras é condição de possibilidade da comunicação linguística). Explicando,

Um discurso que se tenha desenvolvido segundo as regras elaboradas até agora, e nas formas anteriormente analisadas, não supõe uma garantia quanto à correção do resultado. Isso não é assim em relação a algumas normas discursivamente necessárias. A maioria das normas é apenas discursivamente possível. [...] Não é um defeito de uma teoria do discurso que isso seja deixado ao encargo dos participantes no discurso, mas uma de suas vantagens decisivas. (ALEXY, 20। I, f. 137)

Robert Alexy é um dos autores estrangeiros do universo da filosofia do direito mais estudados, traduzidos e citados no Brasil, seja pela doutrina, seja pela jurisprudência. Entretanto, já se constatou, por alguns estudos teóricos e empíricos, que a recepção do pensamento de Alexy foi deturpada, falaciosamente "abrasileirada" de forma a possibilitar ponderações subjetivas, logo discricionárias e arbitrárias, em descompasso com o que defende seu criador. 
Em pesquisa exauriente de Fausto Santos de Morais, em que examina 189 decisões do Supremo Tribunal Federal que citam as teorias de Robert Alexy, há a conclusão de que o pensamento do autor alemão ou não é aplicado, ou é aplicado parcial e equivocadamente, ou é deturpado. Essa foi a recepção pelos juristas ditos seguidores na nossa Corte Maior.

Não foi possível identificar nas decisões analisadas a construção da lei de colisão, como produto do sopesamento realizado no caso concreto. Assim, como propõe Alexy, não há a construção de um suporte ao silogismo da decisão com a indicação das possibilidades fáticas e jurídicas levadas em consideração. $\bigcirc$ que se pode entender, numa especulação, é que a fundamentação da lei de colisão do caso concreto, como visto nas decisões do STF, dificilmente serve para apresentar $\circ$ que foi efetivamente considerado. Essa constatação acaba mostrando o problema da fundamentação das decisões judiciais, servindo, por isso, as críticas quanto ao decisionismo do sopesamento quando desvinculado da responsabilidade argumentativa da apresentação de sua legitimidade (racional). (MORAIS, 20।3, p. 2|8)

Grande contribuição para a teoria da decisão pode ser imputada a Ronald Dworkin. Autor de diversos livros, sempre tendo como pano de fundo uma teoria política liberal, a qual impregna seus textos de um ideal democrático, respeitador dos direitos fundamentais e das individualidades humanas. Suas obras apontam um pesquisador obstinado por encontrar uma resposta correta a cada conflito social.

Utilizou-se de várias metáforas para defender seus posicionamentos, como a do juiz de um jogo de xadrez, ocasião em que explicita a necessidade de se respeitarem as regras do jogo e de conhecê-las a fundo e na origem, chegando a falar que cada participante do jogo teria um direito "enxadrístico" a ser respeitado (DWORKIN, 20 I 0, p. I58). A do juiz Hércules, figura esta do magistrado de capacidade, sabedoria, paciência e sagacidade sobre-humanas, o qual deveria ir às origens investigando e revolvendo as instituições jurídicas até encontrar a resposta correta para cada caso (DWORKIN, 20I0, p. 165). E mais, elaborou a metáfora do romance em cadeia, em que enaltece a necessidade de se respeitar, evoluir e ter coerência para com os julgados anteriores do Tribunal.

Sua teoria do direito como integridade tem como uma das principais contribuições à teoria da decisão o combate à discricionariedade do julgador, talvez o grande mal de herança e inspiração do paradigma filosófico moderno, presente nas diversas formas de positivismos.

De forma sensata, consciente do papel estatal, realística e democrática, Dworkin exige dos representantes do Estado uma postura diferenciada: 
Sem dúvida, é inevitável que alguma instância do governo tenha a última palavra sobre que leis serão efetivamente implementadas. Quando os homens discordam sobre os direitos morais, nenhuma das partes tem como provar seu ponto de vista e alguma decisão deve prevalecer, se não quisermos que a anarquia se instale. Mas esse exemplo de sabedoria ortodoxa deve ser o início, e não o fim, de uma filosofia da legislação e da aplicação das leis. Se não podemos exigir que o governo chegue a respostas corretas sobre os direitos de seus cidadãos, podemos ao menos exigir que 0 tente. Podemos exigir que leve os direitos a sério, que siga uma teoria coerente sobre a natureza desses direitos, e que aja de maneira consistente com suas próprias convicções. (DWOKIN, 2010, p. 286).

Quiçá um dos grandes equívocos quando da interpretação da teoria de Dworkin, em especial ao juiz Hércules, seria tentar dar concretude a tal julgador, tornando-o um ser humano plenipotenciário e absoluto. Tal desastre interpretativo vai de encontro a tudo que foi pregado por Dworkin.

Trata-se de uma figura metafórica, logo imaginária, de postura democrática e respeitadora das instituições jurídicas e das individualidades pessoais. As qualidades que o autor atribui a ele são características que uma teoria da decisão deve buscar incessantemente, sempre no sentido de ter a obsessão de encontrar uma resposta correta diante de cada caso concreto.

Lenio Luiz Streck, rebatendo as críticas feitas à Dworkin, defende:

[...] Dworkin não defende qualquer forma de solipsismo (a resposta correta que defende não é produto da uma atitude de um Selbstsüchtiger). É preciso entender que Dworkin superou - e de forma decisiva - a filosofia da consciência. Melhor dizendo, o juiz "Hércules" de que fala Dworkin é apenas uma metáfora para demonstrar que a superação do paradigma representacional (morte do sujeito solipsista da modernidade) não significou a morte do sujeito que sempre está presente em qualquer relação de objeto. (STRECK, 2014, p. 433-434)

A contribuição da hermenêutica para a análise da interpretação e aplicação do direito está umbilicalmente ligada à teoria da decisão jurídica, fato atualmente inquestionável. $\bigcirc$ crescimento e o amadurecimento crítico de tal ciência, entrelaçando-se com a filosofia do direito, têm o potencial de desvelar o que está por trás do processo de decisão judicial, aquilo que, num olhar acrítico e superficial, não se percebe.

○ tratamento jurídico do fenômeno natural do conflito social foi e sempre será reflexo do paradigma filosófico em que se está situado. 
Nesse sentido, resgata-se o universo antigo, em que se supunha um Mundo organizado, planejado e que cada objeto/coisa teria o seu devido lugar e estaria predeterminado ao desenvolvimento de alguma virtude, tal estrutura é conhecida por "mito do dado". Com isso, numa relação sujeito/objeto, tem-se que este determinaria aquele, pois ao sujeito somente restaria investigar e descobrir o sentido já contido nos objetos. Nessa lógica, entre intérprete e legislação, dá-se força total à legislação, pois ao intérprete resta apenas a atividade subsuntiva de aplicar a lei ao caso concreto, método silogístico, simples, direto e puro.

Com a modernidade, aquecida pelo pensamento iluminista, tem-se a alteração da estrutura de pensamento e modo de ver o universo. Desloca-se para o sujeito o destaque no esquema sujeito/objeto, o que, na seara jurídica, termina por supervalorizar o intérprete e aplicador do direito. Com essa postura, tem-se o desenvolvimento da filosofia da consciência, em que o sujeito torna-se dominador do objeto, formatando o ideal de pensamento até hoje predominante, qual seja, o sujeito cognoscente mediante o objeto cognoscível.

O desenvolvimento das teorias do direito, sob tal paradigma moderno, fortaleceu em demasia o julgador. As várias formas de positivismos jurídicos sempre terminavam por cair, em algum momento, num espaço de atuação com certa liberdade para o juiz. Cita-se o mito da completude do ordenamento jurídico, com as soluções integrativas de analogia em caso de lacuna; a norma de textura aberta de Hart; a aplicação do direito como algo estranho à teoria pura do direito de Kelsen.

O grande direcionamento inovador para a filosofia do direito e para a hermenêutica jurídica foi a "Virada ou Giro Ontológico-Linguístico", em que se muda radicalmente a maneira de se pensar, o paradigma filosófico, tendo o potencial de alteração imensurável sobre todas as ciências. Logo, toda a construção jurídica deve ser reavaliada sob o novo enfoque, num diferente esquema agora sujeito/inguagem - sujeito/linguagem.

O Dicionário de Hermenêutica de Lenio Luiz Streck trabalha nesse sentido:

Esse giro "liberta" a filosofia do fundamentum que, da essência, passara, na modernidade, para a consciência. Mas, registre-se, o giro ou guinada não se sustenta tão somente no fato de que, agora, os problemas filosóficos serão linguísticos, em face da propalada "invasão" da filosofia pela linguagem. Mais do que isso, tratava-se do ingresso prático na filosofia. [...]

Nele [novo paradigma], existe a descoberta de que, para além do elemento lógico-analítico, pressupõe-se sempre uma dimensão de caráter prático-pragmático. (STRECK, 2017, p. 86)

Nesse contexto, um dos maiores expoentes da hermenêutica filosófica é o alemão Hans-Georg Gadamer. Absorvendo a evolução filosófica do estudo da linguagem e da 
condição do ser humano no universo de seu mestre Heidegger, há uma verdadeira mudança paradigmática da maneira de se colocar perante os fenômenos fáticos.

Supera-se a questão do método moderno por uma autoconsciência da condição do homem no mundo, numa verdadeira ontologia do intérprete e de seus condicionamentos existenciais, sua historicidade, o respeito à tradição, o abandono da ilusão da neutralidade mediante as coisas, tudo isso pela linguagem como condição de possibilidade, e não como mero instrumento. Abandona-se o enfoque histórico regressivo, adotando-se um modelo compreensivo atual ontológico numa relação intersubjetiva de "fusão de horizontes".

No entendimento heideggeriano, o homem não pode abandonar sua vida, suas experiências, frustrações, preconceitos, subjetividades, pois ele é e faz parte desse mundo, lançando a ideia de Dasein, de "ser-aí". A historicidade de cada um é sua vida e o acompanha, bem como está em constante atualização. Assim, a ninguém é possível uma neutralidade inicial, não há de se falar em condição zero em qualquer ato interpretativo. $\bigcirc$ que se exige e se espera é a consciência e percepção da sua historicidade, para então saber lidar com ela.

A hermenêutica-filosófica gadameriana pressupõe já estarmos conformados pelas ideias normativas nas quais fomos educados e que sustentam a ordem de toda vida social. Ressaltando que tais perspectivas podem ser alteradas criticamente. Nesse sentido, aquele que busca compreender algo, necessariamente já carrega consigo uma antecipação que o interliga com aquilo que busca compreender, uma espécie de consenso de base. É o reconhecimento da tradição, bem como a imersão nela do intérprete.

Heidegger não vê outro caminho à ciência que não seja a filosófica:

A ciência só é possível como filosofia. Como transcender expresso - postura fundamental -, porém, a filosofia fornece a cada ser-aí a possibilidade originária de questionar o próprio ser-no-mundo segundo seu apoio e postura. Filosofar como deixar acontecer a transcendência é a liberação do ser-aí. $\bigcirc$ que é liberado é a liberdade do ser-aí e a liberdade só é na liberação. (HEIDEGGER, 2009, p. 429)

Partindo-se da historicidade, tem-se a pré-compreensão daquilo a ser interpretado. Com isso, num ato conjunto e contemporâneo, ocorre a compreensão, viabilizadora da interpretação. Não há se falar em sequência de atos ou autonomia entre eles, mas sim num todo complexo e com implicações recíprocas. Assim, compreende-se pela pré-compreensão (a qual é forjada na historicidade individual), para então se interpretar, sendo tal fenômeno um ato criativo, pois inovador. Continuando, a cada ato criativo de interpretação, absorvem-se mais elementos que implicam alteração na historicidade, logo na pré-compreensão e assim de forma cíclica e sucessivamente. Com isso, forma-se um círculo hermenêutico indefinido da compreensão, 
segundo o qual "devemos compreender o todo a partir do singular e o singular a partir do todo" (GADAMER, 20। I, p. 72).

Importante o alerta feito por Lenio Luiz Streck em seu Dicionário Hermenêutico:

Círculo hermenêutico, todavia, não é um conceito ou uma tese para ser instrumentalizada, isto é, não pode ser um mecanismo ad hoc para ornamentar discursos jurídicos. Círculo hermenêutico é a antítese de qualquer cisão estrutural que se faça entre texto e norma ou entre regra e princípio. Também esse valioso conceito nada tem a ver com raciocínios feitos por partes, como se fosse possível separar interpretação e aplicação ou questão de fato-questão de Direito. [...] É preciso compreender que o círculo hermenêutico é, justamente, o elemento desconstrutor de qualquer esquema fundado na relação sujeito-objeto. (STRECK, 2017, p. 31)

Gadamer reforça o papel da hermenêutica como sendo uma tarefa teórica e prática. Nessa linha, o hermeneuta filosófico deixa claro que a tarefa de busca do direito e do juízo correto implica uma inevitável tensão, já analisada por Aristóteles: a tensão entre a universalidade da legislação vigente - codificada, ou não, - e a particularidade do caso concreto. A aplicação da lei pressupõe sempre uma interpretação correta, bem como toda aplicação de uma lei ultrapassa a mera compreensão de seu sentido jurídico e termina, invariavelmente, por criar uma nova realidade. A aplicação da lei num caso particular implica um ato interpretativo, o qual é criativo como se viu, concretizando e aprimorando o sentido da lei.

Portanto, a melhoria da qualidade das decisões judiciais passa pelo estudo aprofundado de teoria da decisão. Não se está defendendo esta ou aquela teoria da decisão, o que se está exortando nesta pesquisa é apenas a urgente e obrigatória necessidade de que os aplicadores do direito ao caso concreto - magistrados - passem a se dedicar a tal temática.

\section{O PAPEL DAS ESCOLAS DA MAGISTRATURA E DAS FACULDADES DE DIREITO}

Do exposto, observa-se facilmente que o Judiciário deve reagir e prestar um melhor serviço de entrega de justiça. Ficou evidenciado que uma das ferramentas utilizadas por alguns tribunais, para enfrentamento dos números asfixiantes, foi a figura do juiz-gestor.

Somando-se a isso, ficou muito clara também a necessidade e urgência de as atenções serem voltadas à maneira como os juízes decidem, à qualidade das decisões judiciais no sistema de justiça brasileiro, o que ora se defende seja feito via teoria da decisão.

Alerta-se que a amarra legal em que se justificava não poder ingressar em tal seara, pois livre e íntima a cada juiz, foi revogada pelo novo Código de Processo Civil. 
O Código, de 1973, dizia, no seu artigo 131, que o juiz deveria apreciar livremente a prova e indicar os motivos que formaram seu convencimento. Porém, o Código de Processo Civil, 20 I 5, no artigo 37I, retirou o termo "livremente" e declara agora que o juiz deve apreciar a prova, indicando na decisão as razões de seu convencimento. Assim, o antes quase intocável princípio do livre convencimento motivado do juiz deve sofrer atualização, e não mais pode ser visto como um entrave para o desenvolvimento de uma teoria que adentre, discuta e critique o porquê das decisões judiciais.

O desenvolvimento de uma teoria da decisão judicial é imperioso e caminho sem volta a ser trilhado por nossa justiça. Não se trata de um método, nos moldes de paradigmas da modernidade, mas sim de uma preocupação hermenêutica de cunho filosófico, envolvendo questões teóricas e práticas.

Levando-se em conta que o desenvolvimento hermenêutico na história sempre foi uma tarefa teórica e prática, conforme entendimento gadameriano (GADAMER, 201 I, p. 349-369), defende-se que as Escolas da Magistratura dos Tribunais brasileiros têm o dever de dar mais destaque a tais problemáticas apontadas, pois são as responsáveis pela seleção pública, formação inicial, capacitação e atualização profissional do corpo de magistrados brasileiros. Para tal, deve contar com o suporte crítico e investigativo das academias - Faculdades de Direito.

Com isso, exorta-se que as provas do processo de seleção de magistrados já deveriam exigir gestão processual e teoria da decisão (Resolução n 75, de 2009, do Conselho Nacional de Justiça); os cursos de formação inicial da carreira de magistrado, bem como aperfeiçoamento e atualização, já deveriam trabalhar com disciplinas relacionadas a como os juízes conseguem superar a grande demanda e como devem decidir. Inadmissível continuar selecionando e formando julgadores com a crença de que atuarão em condições perfeitas na prática, bem como que sua íntima convicção é inviolável e inquestionável.

Ficou evidente a necessidade de as instituições que formam inicialmente os magistrados reagirem e passarem a enfrentar os temas. Para fortalecimento da própria Magistratura, melhoria da prestação jurisdicional, celeridade, segurança jurídica e qualidade das decisões.

A complexidade do tema é tamanha que somente será superada quando do entrelaçamento de esforços do universo teórico-acadêmico com o mundo prático das Escolas da Magistratura. Todas as construções teóricas devem sofrer um processo de entrechoque com a prática forense, como numa espécie de teste de viabilidade real. Assim, doutrinadores e juízes têm de dar as mãos, bem como Faculdades de Direito e Escolas da Magistratura devem ter o mesmo escopo, somente todos juntos podem construir uma forma de se chegar à melhor decisão judicial.

Tal desiderato só será possível se forem eliminados pedantismos de ambos os lados. 


\section{CONCLUSÃO}

O exercício da prestação jurisdicional tem a necessidade de ajustes, pois é alvo de várias críticas. Nesse sentido, uma das técnicas de enfrentamento que tem sido adotada por tribunais é o desenvolvimento de uma postura de gestão por parte dos magistrados.

Revelaram-se inúmeras atividades cotidianas inerentes à atividade do juiz a exigir seu ingresso no universo da administração pública. Ademais, ficou comprovado que a enorme demanda de processos exige um planejamento estratégico prévio pelo julgador.

Evidente, pois, que o conhecimento técnico de gestão pública judiciária contribui sensivelmente para uma prestação jurisdicional mais célere e eficiente, seja de forma exógena - relacionamento com os demais órgãos do Poder Executivo e do Poder Legislativo - ou de forma endógena - interno ao próprio Poder Judiciário.

Portanto, confirmou-se a primeira hipótese vislumbrada inicialmente pela necessidade de que o juiz deva ter conhecimento teórico para uma gestão correta do serviço de prestação jurisdicional, que permita uma atuação duplamente técnica, matéria jurídica e de administração pública, resultando numa maior efetividade do direito.

Após os apontamentos e breves comentários acerca dos contributos da filosofia do direito e da hermenêutica, concluiu-se pela impossibilidade de se importar teorias da decisão de outros países, sob pena de frustrações e insucesso. Portanto, necessário o desenvolvimento de uma teoria da decisão perfeitamente adaptada às peculiaridades brasileiras, com a participação dos doutrinadores e dos juízes.

Com a hermenêutica filosófica, ficou completamente afastado o paradigma moderno do sujeito, acarretando a necessidade de que qualquer desenvolvimento de teoria seja obrigatoriamente via interação intersubjetiva com e pela linguagem.

Reconhecendo-se a crescente complexidade das relações sociais, somando-se com as dificuldades de o julgador ter de extrair uma resposta jurisdicional do ordenamento jurídico pátrio, apoiado na história do desenvolvimento da hermenêutica filosófica, conforme defende Gadamer, concluiu-se que o único caminho viável e possível para se trilhar uma teoria da decisão judicial é o esforço conjunto entre teoria e prática.

Portanto, mister se faz um somatório de esforços entre o universo teórico-acadêmico dos doutrinadores (Faculdades de Direito) e o universo prático dos julgadores (Escolas da Magistratura), somente assim se conseguirá formatar o caminho para uma teoria da decisão que seja capaz de superar a contento a tensão entre o ordenamento jurídico e o caso concreto colocado, bem como fornecer ao magistrado instrumentos para minorar a excessiva quantidade de processos.

Por fim, desiderato final e maior deste artigo, como forma concreta de enfrentamento dos problemas do excessivo número de processos e da qualidade das decisões judiciais, exortam-se as Escolas da Magistratura dos Tribunais brasileiros para que incluam, definitivamente e de forma aprofundada, as temáticas de gestão judiciária e de teoria da decisão nos seus planos de estudo dos cursos de formação inicial e continuada ofertados aos magistrados. Ainda que tais disciplinas sejam desenvolvidas com a participação real e efetiva de especialistas do universo acadêmico das Faculdades de Direito. 
O JUDICIÁRIO BRASILEIRO E SUAS ANOMALIAS: QUANTIDADE DE PROCESSOS E QUALIDADE DAS DECISÕES

\section{REFERÊNCIAS}

ALEXY, Robert. Teoria da argumentação jurídica: a teoria do discurso racional como teoria da fundamentação jurídica. Tradução Zilda Hutchinson Schild Silva; revisão técnica da tradução e introdução à edição brasileira Claudia Toledo. 3. ed. Rio de Janeiro: Forense, 20 I I.

ALEXY, Robert. Teoria dos Direito Fundamentais. Tradução Virgílio Afonso da Silva da 5. ed alemã. 2. ed; 5 tiragem. São Paulo: Malheiros Editores Ltda, 2017.

ALVES DA SILVA, Paulo Eduardo. Gerenciamento de processos judiciais. I. ed. São Paulo: Saraiva, 2010.

BUSTAMANTE, Thomas da Rosa de. Teoria do Direito e Decisão Racional: temas de teoria da argumentação jurídica. I. ed. Rio de Janeiro: Renovar, 2008.

CALHAO, Antônio Ernani Pedroso. O princípio da eficiência na administração da justiça. I. ed. São Paulo: RCS, 2007.

DIAS, Rogério A. Correia. Administração da Justiça: a gestão pela qualidade total. I ed. Campinas: Millennium Editora, 2004.

DUARTE, Écio Oto Ramos. Teoria do discurso e correção normativa do direito: aproximação à metodologia discursiva do direito. 2. ed. rev. São Paulo: Landy Editora, 2004.

DWORKIN, Ronald. Levando os direitos a sério. Tradução de Nelson Boeira. 3. ed. São Paulo: WMF Martins Fontes, 2010.

FREITAS, Vladimir Passos de e FREITAS, Dario Almeida Passos de (coords.). Direito e administração da justiça. Curitiba: Juruá, 2012.

GADAMER, Hans-Georg. Verdade e método II: complementos e índice. Tradução de Enio Paulo Giachin; revisão da tradução de Márcia Sá Cavalcante. 6. ed. Petrópolis: Vozes; Bragança Paulista: Universitária São Francisco, 20 I I.

HADDAD, Carlos Henrique Borlido e PEDROSA, Luís A. Capanema. Administração judicial aplicada. I ed. Porto Alegre: Sergio Antonio Fabris, 2014.

HEIDEGGER, Martin. Introdução à filosofia. Tradução Marco Antonio Casanova; revisão de tradução Eurides Avance de Souza; revisão técnica Tito Lívio Cruz Romão. 2 ed. São Paulo: WMF Martins Fontes, 2009.

MORAIS, Fausto Santos de. Hermenêutica e Pretensão de Correção: uma revisão crítica da aplicação do princípio da proporcionalidade pelo Supremo Tribunal Federal. Tese de doutoramento apresentada na Unisinos: São Leopoldo, 2013. 
REIS, Wanderlei José dos. Diretoria de foro e administração judiciária. I. ed. Curitiba: Juruá, 2010.

SLAIBI FILHO, Nagib. Magistratura e Gestão Judiciária. I ed. Rio de Janeiro: Editora Forense, 2016.

STRECK, Lenio Luiz. Dicionário de hermenêutica: quarenta temas fundamentais da teoria do direito à luz da crítica hermenêutica do direito. I. ed. Belo Horizonte: Letramento: Casa do Direito, 2017.

. Jurisdição e ausência de uma teoria da decisão. Revista de Derecho de la Pontifícia Universidad Católica de Valparairo, $n^{\circ} 4$ I. Disponível em: http // www. scielo.cl/scielo.php?script=sci_arttext\&pid=S07| 8-685 I 20130002000 I7. Acesso em: $16 / 10 / 2017$.

; OLIVEIRA, Rafael Tomaz de e TRINDADE, André Karam. O "cartesianismo processual" em terrae brasilis: a filosofia e o processo em tempos de protagonismo judicial. Revista NEJ - Eletrônica, Vol. 18 - n. I - p. 05-22 / jan-abr 20।3. Disponível em: http://dx.doi.org/l0.14210/nej.v|8n I.p5-22. Acesso em: 29 de outubro 2017.

. Verdade e consenso: constituição, hermenêutica e teorias discursivas. 5 ed. rev., mod. e ampl. São Paulo: Saraiva, 20।4.

TRINDADE, André Karam. Robert Alexy e a vulgata da ponderação de princípios. Disponível em: htttp://www.conjur.com.br/20 I3-nov- I6/diario-classe-robert-alexyvulgata-ponderacao-principios?, Acesso em: 15/10/2017.

VALLE, Marcus Vinícius Mendes do. Gestão estratégica de unidades judiciárias. Desdobramento de $4^{\circ}$ nível: gestão judiciária aplicada. I. ed. Belo Horizonte: Conhecimento, 2017.

Recebido em: 28/08/2018

Aprovado em: 05/06/2019 